\title{
Climate Policy and Ecological Modernization Processes in the Republic of Kazakhstan and Russia
}

\author{
Yury Kovalev, Alexander Burnasov*, Anatoly Stepanov, and Maria Ilyushkina \\ Ural Federal University, Lenin Str., 51, 620027 Ekaterinburg, Russia
}

\begin{abstract}
The article examines the climate policy of Russia and Kazakhstan in the period between the years 1990 and 2020. The position of the countries during the international negotiations on the formation of global climate regimes, the causes and factors affecting foreign and domestic climate policy are analyzed. The main actions and institutional changes in Russia and Kazakhstan aimed at the achievement of climate commitments are considered as well. Moreover, the key national programs on ecological modernisation of farms are discussed. The ecaluationt of the development level of various instruments of climate policy in both countries is provided. In conclusion the comparative scheme of climate activities in Russia and the Republic of Kazakhstan , designed by the authors, is presented.
\end{abstract}

\section{Introduction}

Global climate change is a key ecological problem of the XXI century. Over the past 40 years, the continuant increase in annual temperatures has been observed. In this regard, Russia and Kazakhstan are not the exceptions. On the contrary, the increase in average annual temperatures exceeded global indicators. In 2020, in the eastern regions of Russia the monthly average temperature was by $10 \mathrm{C}$ degrees higher, in Verkhoyansk the air warmed up to $38 \mathrm{C}$ in June [1]. Abnormal heat with a temperature of more than $40 \mathrm{C}$ was fixed in the same summer in the western regions of Kazakhstan [2]. An increase in the air temperature leads to a rise in the frequency and intensity of droughts, floods, hurricanes, and other extreme weather conditions. Both countries are characterized by a rise in the number of forest fires, problems with water supply and agriculture.

The problem of global climate change has created a new political field called climate policy. It is rather complex and includes institutional, scientific, technological and economic policies of the countries [3]. Russia and the Republic of Kazakhstan are important international "players" in this sector of world politics. Since 1990 (the second UN Climate Conference), these countries have been actively participating in the promotion of international documents on climate protection on our planet. Russia and Kazakhstan signed and ratified United Nations Framework Convention on Climate Change (1995 and 1999). Due to the ratification of the Kyoto Protocol in Russia at the end of 2004, it became

* Corresponding author: burnasov@mail.ru 
the first major document determining the mechanisms and instruments of international climate policy. In December, 2015 Russia and Kazakhstan signed the Paris Agreement. Kazakhstan ratified it in December, 2016. Russia did it in October, 2019. In December, 2020 the President of Kazakhstan announced the goals of achieving carbon neutrality of the country by 2060 . The position of countries on international treaties was characterized as "voluntary commitments for all" up to the signing of the Paris Agreement (Kazakhstan made this statement at the Conference of the parties No. 4, in 1998 (COP 4), Russia at COP 12 in Nairobi (COP 12), in 2006).

Despite this, the climate policy of these countries is characterized by low ambition and a slow pace of institutional and economic transformations. According to the climate protection index, Russia and Kazakhstan belong to the group of countries with a "very low" degree of protection (52nd and 54th place, respectively). In terms of the level of RES implementation, they are ten times inferior to the EU countries, China and other countries (for example, the percentage of RES in electricity production in the EU is $20 \%$, in China $10 \%$, at the same time in Russia it is up to $0.28 \%$, Kazakhstan - $1.4 \%$ ) [4].

One of the main barriers to serious environmental modernization of the economy is the high dependence of the socio-economic development of Russia and Kazakhstan on the extraction and export of fossil fuels. The percentage of oil and gas in the structure of their exports exceeds $60 \%$. The obligation to reduce greenhouse gas (GHG) emissions in Kyoto and post-Kyoto periods of the development of international climate policy would inevitably have hit the oil and gas complex of these countries, reflected in a sharp decline in the income of the companies. However, the formation of a new international climate regime, based on the Paris Agreement, creates conditions for a broad environmental modernization of their economic complex, involving them in international trade in "green" technologies, services, etc. Moreover, without these actions and global integration in the new climate regime Russia and Kazakhstan might face technological, economic and social regression.

The purpose of the current research is to analyze the features of climate policy and environmental modernization processes in Russia and Kazakhstan in the period 1990-2020; to identify common features and differences in the implementation of the policy; to determine and assess the level of institutional changes in this area. In conclusion, the authors propose the scheme for comparing the climate policy and the processes of environmental modernization of the two countries.

The study of climate policy and the processes of environmental transformations of national systems has been addressed in the works of V.I. Danilov-Danilyan (2015), A.A. Averchenkov (2009), A.O. Kakorin (2013), Yu.A. Rusakova (2016), etc. [5]. Significant contributions to the study of climate policy and environmental transformation were made by O. Edenhofer (2017), G. Simonis (2017) (Hein 2017, Otto 2017, Simonis, 2017) [6, 3], BRICS countries (Leal-Arcas 2013; Gupta 2014; Gladun, Ashan 2016; Downie, Williams 2018) $[7 ; 8 ; 9 ; 10]$. The evolution issues of international climate policy have been thoroughly studied so far. The comparative analysis of climate policy and environmental transformation processes in different countries is less well presented [11]. There is a particularly large deficit in research on climate policy and environmental modernization processes in the post-Soviet space (Sheludkov, 2015) [12]. The comparison of climate policies and environmental modernization processes in the former USSR, the the problems of the transition to a low and carbon-neutral economy is seen as a relevant field of socioeconomic research.

\section{Materials and Methods}

The authors of the current article continue the series of research projects. The climate policy of the Baltic region countries has already been considered together with the key 
factors for reducing CO2 emissions in the period 1990-2018. Correlations between the processes of decarbonization and the ecological transformation of farms have been demonstrated [13]. The next research presents the features of the negotiation process for the protection and use of the world biodiversity. Moreover, it outlines the main stages of development of the mechanisms for biodiversity protection [14].

The theoretical basis of this study is formed by the theory of "collective goods" of the American economist M. Olson and the concept of "path dependence" (D. North, P. David, G. Grabher, A. Azuan) [15]. M. Olson explains the behaviour of actors in relation to "collective goods" which is the Earth's atmosphere in this study [16]. Reducing GHG emissions through environmental modernization of the economy is becoming an important factor in preserving collective goods. However, since some subjects of international relations tend to consume the collective goods without the desire to pay for their own expensive environmental modernization, according to M. Olson, they act as "free-riders". In regard to this, the efforts of countries to stabilize the climate will be useless if other countries do not implement such measures. This makes the negotiation process on the formation of an international climate regime extremely difficult. The creation of global mechanisms of universal responsibility affects the "climate" behaviour of certain countries. The establishment of a system of international trade in GHG emissions quotas and the requirement of commitments to reduce them for all countries are the important steps in the right direction. The signing and ratification of the Paris Agreement, which implies the adoption of commitments to reduce GHG, strengthens the processes of environmental transformation in Russia and Kazakhstan. Otherwise, Sam Adelman provides a critical evaluation of the effectiveness of the Paris Agreement in protecting the rights of especially vulnerable communities [17].

Within the second theory which implies the concept of the "path dependence", climate policy can be considered as a project of socio-economic modernization. The ecological transformation of the economy is seen by a number of researchers as a transition of the society to a new level of technological development [18]. However, environmental modernization meets with the tangible obstacles. There are significant differences in the speed of implementation of the goals and objectives of climate policy, as well as the pace of environmental modernization of national economies of the world. Some countries act as world leaders in environmental transformation. Others play the role of outsiders. Hydrocarbon dependence of the economy becomes a deterrent to transformations. This is reflected not only in the speed of the implementation of environmental technologies but also in the attitude of the society and political elites to the global climate problem [19].

The methodological basis of this article is formed by the structural, analytical and comparative approaches. The analysis of the positions of countries reflected in the declarations of climate conferences of the parties (COP), national climate strategies and national statistics allow to determine the directions and achievements in the climate policy, to assess the impact of various factors (external and internal) on the processes of environmental modernization of national structures. The main sources on which the statements and conclusions of this publication were based were data from the static services of the Russian Federation and the Republic of Kazakhstan, declarations of climate conferences (Conferences of the Parties), national documents in the field of climate protection and environmental modernization.

\section{Results and Discussion}

Greenhouse gas (GHG) emissions into the planet's atmosphere are the main causes of global climate change. The goal of the international climate policy is to stabilize the climate on Earth by reducing GHG emissions. The formation of international climate regimes 
occurs as a result of negotiations between the countries in the development of a common policy. Russia and the Republic of Kazakhstan are important actors in the global climate diplomacy, and at the same time the largest producers of anthropogenic greenhouse gases. Their total emissions in 2019 amounted to 2.6 billion tons of CO2 equivalent. Russia accounted for about $85 \%$ of the total emissions of the two countries and, respectively, $15 \%$ of Kazakhstan [20].

In the period 1990-2019, the dynamics of GHG emissions in both countries was cyclical. In Kazakhstan a constant decline was observed during the 1990s. In 2001 greenhouse gas emissions in the Republic of Kazakhstan fell by more than half (from 401 million tons to 198 million tons); their CO2 emissions almost doubled (from 281 to 142 million tons). As a result, 2001 became the year with the absolute minimum of national emissions. Since 2002 in Kazakhstan there has been a constant increase in emissions. In 2019 the indicators were 396.5 million tons of GHG.

In the period 1990-2019 in Russia, CO2 emissions decreased by 26\% (from 2393 million tons to 1792 million tons) (Fig.1). The peak of the cuts was observed in the late 1990 s, which was caused by a sharp decline in industrial production in the country. A similar phenomenon of GHG emissions reduction was observed in all the republics of the former USSR and the post-socialist countries of Eastern Europe.

The deindustrialization of the economies of Russia and Kazakhstan was accompanied by its restructuring in favour of raw materials and polluting industries. On the contrary, high-tech industries disappeared. As a result, the structure of greenhouse gas emissions in Russia and Kazakhstan has significant differences from emissions in other countries of the world. If the energy complex accounts for an average of $33 \%$ of GHG emissions worldwide, in Russia and Kazakhstan, it is 79 and $82 \%$, respectively, The percentage of industry, on the contrary, is two or more times less than the average global. For this reason, the reform and renewal of the energy sector in both countries should have the highest priority in the implementation of their climate policies.

It is necessary to focus on the analysis of the position of Russia and Kazakhstan in international negotiations on the formation of a global climate regime and their impact on the processes of environmental modernization in these countries in more detail.

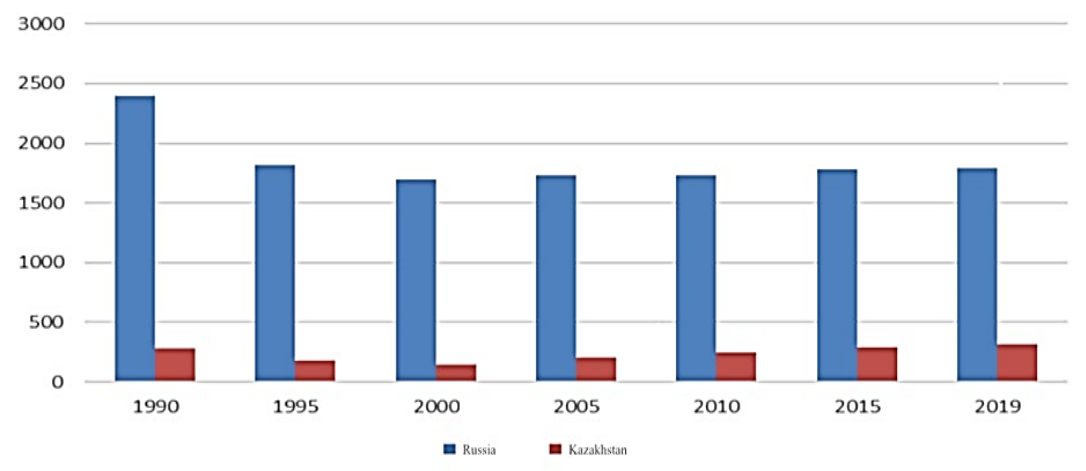

Source: Bureau of National Statistics of the Republic of Kazakhstan, Rosstat.

Fig. 1. Dynamics of CO2 emissions in Russia and Kazakhstan in the period 1990-2019 (million tons).

Russia and Kazakhstan have been active players in the global climate policy. At the second Conference on Climate Change (Geneva, 1990), they joined the Intergovernmental Negotiating Committee for a Framework Convention on Climate Change. In May, 1992 the convention was signed by more than 190 countries of the world. The main goal of the 
document is "to stabilize the concentration of greenhouse gases in the atmosphere at the level, which will allow to prevent dangerous anthropological interference in the climate system of the planet" [21].The countries agreed to implement measures to reduce greenhouse gas emissions. However, the serious economic crisis that occurred as a result of the collapse of the socialist system and the collapse of the USSR led to a sharp reduction in greenhouse gas emissions in these countries. In Russia they decreased by $30 \%$ in the period of 1990-1995, and in Kazakhstan by more than 32\% [22].

At further climate conferences Russia and Kazakhstan were members of the Umbrella Group of the countries that collectively represent their interests in climate diplomacy. This group includes the United States, Canada, Australia, Norway and New Zealand and is characterized by a "weak" climate policy, low ambitions in assuming international obligations in the fight against global warming. The protection of the traditional, national energy complex is the main priority of their foreign policy. The huge role of fuel and energy resources in the economies of these countries is reflected in their climate protection index. The countries of the Umbrella Group together with the OPEC countries have the worst positions in this indicator [23]. Nikolai Dronin and Alina Bychkova point out the difference in the perception of two global issues by American and Russian environmental scientists which lies witin stratospheric ozone depletion and climate change [24].

Russia has lagged behind in its climate mitigation policy. It joined the 1997 Kyoto Protocol in 2004, later than the majority of other parties. Moreover, it participated in the Protocol's first commitment period (2008-2012) without adopting any serious mitigation measures [17]. This period coincides with Dmitry Medvedev's four years of presidency, marked by a brief moment of increased engagement in energy efficiency and economic modernization campaigns. The country then refused to sign up to the second Kyoto period, which began in 2013, but agreed to join the next stage by signing the Paris Agreement (PA) in 2016. Again, it was one of the last to ratify the PA in September 2019. Furthermore, even though Russia joined the Clean Energy Ministerial, it leads and participates in fewer initiatives than other members [25]. Henry, Laura A and Lisa McIntosh Sundstrom account for the gap between Russia's weak initial implementation of the Kyoto Protocol and its more active engagement in climate policy during the Medvedev presidency [26]. According to the Kyoto Protocol, Russia was allowed to remain at the level of 1990 in terms of greenhouse gas emissions by 2012 [27]. Kazakhstan was not included in the list of the countries with mandatory quotas. The next year after the Kyoto Conference, at the summit in Buenos Aires, the Republic of Kazakhstan together with Argentina, announced the adoption of voluntary commitments to reduce emissions. Thus, the Republic of Kazakhstan and Argentina wanted to set an example for other developing countries to make commitments. Unfortunately, this initiative was not supported, as 77 countries of the group insisted on adhering to the UNFCCC principle of "common but differentiated responsibilities".

The international climate diplomacy of the late XX century focused on the early ratification of the Kyoto Protocol by the countries. After the refusal of the United States and Australia to ratify it (the leaders of the Umbrella Group) all hopes were turned towards Russia. The Russian diplomacy did not miss to use this situation. In 2001 at the Marrakesh Summit (COP 7) Russia put forward a demand for a double increase in the ability of its natural sinks to absorb $\mathrm{CO} 2$ (when calculating national emissions). Therefore, some of the commitments to reduce emissions could be fulfilled by simply including and expanding the calculation system for natural areas. Interested in keeping Russia in the negotiation process and in its speedy ratification of the Kyoto Protocol, the European Union agreed on the demands of Russia (Decision 12/CP7). The final document of the conference in Marrakech emphasizes "the importance of developing and disseminating innovative technologies in key sectors of the economy, including energy" [28]. At the same conference Kazakhstan 
became a member of another group of countries for negotiations within the framework of the UNFCCC: Central Asia and the Caucasus, Albania and Moldova (CACAM). Since then, the common interests of the Republic of Armenia, Georgia, Uzbekistan, Turkmenistan, Moldova and Albania have been defended together with Kazakhstan [29].

The process of ratification of the Kyoto Protocol was complicated in both countries. For some Russian scientists anthropogenic warming was not a proven fact. A suggestion was made that the ratification of the Kyoto Protocol would have a negative impact on the economy of the country. After the entry into force of the Kyoto Protocol (Russia ratified it at the end of 2004) the Mazhilis of Kazakhstan held a public debate on the ratification of the protocol. By 2006, it had prepared a Report on the assessment of the economic impact of the Kyoto Protocol and the prospects for Kazakhstan on the hydrocarbon market. Great hopes were connected with the implementation of environmental and energy projects in the country at the expense of foreign investment. In 2009 Kazakhstan ratified the Kyoto Protocol.

The second decade of the XXI century in global climate policy was marked with attempts by the world community to extend the Kyoto protocol and create a global climate treaty for the period after the year 2020. A comparison of the climate policy in two countries during this period shows a significant advance of Kazakhstan both in terms of the ambition of the climate policy goals, the timing of the implementation of international treaties, and the pace of internal institutional changes. In 2011 Russia refused to participate in the extension of the Kyoto Protocol for the period after 2012. Hopes for an inflow of huge financial foreign investments through the mechanisms of the Kyoto Protocol were not fulfilled [12]. In 2009 Russia adopted the climate doctrine. It noted that "climate change is one of the most important international problems of the XXI century which goes beyond the scientific problem, and is a complex interdisciplinary problem that covers the environmental, economic and social aspects of sustainable development of the Russian Federation" [30]. In April, 2011 the Government of the Russian Federation approved a plan for the implementation of the climate doctrine until 2020. According to it, Russia commits to implement a comprehensive climate policy, take measures to adapt to climate change, mitigate anthropogenic impacts on the climate and strengthen international cooperation in this area [31].

In December, 2015 Russia signed the Paris Agreement, ratified it in 2019 and in November, 2020 presented to the UN its nationally determined contribution to the implementation of the Paris Agreement. At the same time, in November of the same year, the President of the Russian Federation ensured a reduction in greenhouse gas emissions by up to $70 \%$ compared to the level of 1990. Since January 1, 2015 the updated law "On Environmental Protection" (219-FL) has been in effect in Russia.

The mechanisms of the Kyoto Protocol practically are not applicable on the territory of Russia. In February, 2021 a draft law on limiting greenhouse gas emissions was submitted to the State Duma, which provides the creation of tools for implementing climate projects aimed at reducing greenhouse gas emissions. Unlike Russia, Kazakhstan has implemented important institutional changes since 2010 from the point of view of environmental transformation of the economy. First of all, it is the creation of a national market for trading quotas for greenhouse gas emissions. In this regard, the Republic of Kazakhstan is one of the world leaders. In 2015 a new set of trade rules was established. The Environmental Code of the country (Paragraph 9.1.) defines the rules for the distribution of quotas for greenhouse gas emissions in the Republic of Kazakhstan. On the basis of this regulation, the national plans for their allocation have been approved in the country since 2013. In January, 2021, the government adopted another plan for one year. The price of one ton of CO2 in December, 2020 was $\$ 1.19 \mathrm{~m}$, which was ten times lower than the cost of certificates of quotas of foreign representatives. The low price of quotas can become one of 
the factors of increasing demand for national certificates, which will serve as the income source for the national economy in the post-carbon period.

Other important steps in the direction of ecological modernization of the economy in order to reduce emissions, in accordance with Article 4 of the UNFCCC and Articles 2 and 3 of the Kyoto Protocol, were the law "On Energy Saving and Energy Efficiency Improvement" approved by the President of Kazakhstan, defining new rules in energy consumption (January, 2012), and the concept of the transition to a "green economy" (May, 2013). Its aim is to "create a competitive, highly innovative economy that allows the country to become one of the 30 most developed countries in the world while minimizing the burden on the environment" [32]. The concept is expected to be implemented in three stages. The first one (2013-2020) provides for optimizing the efficiency of resource allocation and consumption; the second (2020-2030) is for large-scale implementation of renewable energy, energy-saving technologies and rational use of natural resources; the third (2030-2050) envisages a complete transition to a green growth model. The transition to a new economic model can increase the energy efficiency of the economy of Kazakhstan by $40-60 \%$, reduce water consumption by $50 \%$ and create more than 500 thousand jobs in both old and new industries. In December, 2020 at the virtual summit of the Conference of the Parties (COP 26) the President of Kazakhstan announced the goals of achieving carbon neutrality by 2060 . It is obvious that its implementation will require a revision of the concept of transition to a green economy with its previously approved goals of $30 \%$ RES by 2030 and $50 \%$ by 2050 . Kazakhstan's greenhouse gas emissions continue to rise reaching 1990 levels in 2018.

A comparison of the nationally determined contributions of Russia and Kazakhstan in the framework of the implementation of the Paris Agreement shows their differences and similarities. Kazakhstan introduced its NDC on 6.12. 2016 almost a year after signing the Paris Agreement. According to the national plan, Kazakhstan should reduce greenhouse gas emissions regardless of the influence of internal and external factors by $15 \%$ from the level of 1990 [33]. By improving the efficiency of energy distribution, reducing energy consumption, widespread implementation of clean technologies and renewable energy sources Kazakhstan plans to achieve these goals.

The Russian Federation was one of the last in the list of 191 countries in the world to submit its nationally determined contribution to the implementation of the Paris Agreement (25.11.2020). Russia aims to reduce its greenhouse gas emissions by $70 \%$ by 2030 which is relative to the 1990 level (an actual 30\% reduction). Unlike Kazakhstan, which relies on the concept of transition to a "green economy", the emphasis in Russia is on "the maximum possible absorption capacity of forests and other ecosystems". Further, it is stated that this indicator is determined on the basis of the need to ensure the economic development of the Russian Federation on a sustainable basis, as well as the protection and improvement of the quality of sinks and accumulators of greenhouse gases, and is aimed at achieving the goals of the Paris Agreement. The section "Information on planning processes" describes three key points of the Russian climate policy: 1. Providing financial and technological assistance to developing countries on the "shoulders" of developed countries; 2. Focuses on preserving and increasing the absorption capacity of forests and other ecosystems; 3 . Considers unacceptable the use of the Agreement and its mechanisms as a tool for creating barriers to the sustainable socio-economic development of the Parties to the Convention. Thus, it is obvious that Russia, despite the announced projects aimed at improving energy efficiency, monitoring and forming a market for greenhouse gas emissions, remains committed to the old, traditional economic structures in its development. The energy and fuel complex will continue to shape the country's socio-economic development in the next 10-20 years. According to a report of the World Bank experts, the consequences of this policy can be very serious. 


\section{Conclusions}

A comparative analysis of the climate policy and the processes of ecological transformations of the economy of Russia and the Republic of Kazakhstan demonstrates the presence of both common features and differences. In their foreign policy on climate stabilization Russia and Kazakhstan have advocated the principle of "commitment for all and in all". However, the difficulties of its implementation in the Kyoto and post-Kyoto period of climate policy development, and the dominance of the principle of "common but differentiated responsibilities", in which developed countries assume high obligations and developing countries demand unlimited economic growth hindered the modernization of the economies. As a result, the reduction of greenhouse gases in the study period was insignificant, and it was determined primarily by the economic crisis that was in these countries in the 1990s. Generalizing the international climate policy of two countries during this period, it can be described as indecisive, weak and low-ambitious. The formation of a new climate regime (from 2020) creates conditions for a deep ecological modernization of the economy of these countries (Table 1).

Table 1. Comparison of climate policy and environmental modernization processes in Russia and the Republic of Kazakhstan.

\begin{tabular}{|l|l|l|l|l|l|}
\hline & $\begin{array}{l}\text { Participa } \\
\text { tion in } \\
\text { the } \\
\text { formatio } \\
\text { n of the } \\
\text { internati } \\
\text { onal } \\
\text { climate } \\
\text { regime } \\
\text { (UNFCC } \\
\text { C, Kyoto } \\
\text { Protocol, } \\
\text { Paris } \\
\text { Agreeme } \\
\text { nt) }\end{array}$ & $\begin{array}{l}\text { existence } \\
\text { of a } \\
\text { compreh } \\
\text { ensive, } \\
\text { national } \\
\text { concept } \\
\text { for the } \\
\text { transitio } \\
\text { n to a } \\
\text { green } \\
\text { economy }\end{array}$ & $\begin{array}{l}\text { existenc } \\
\text { e of a } \\
\text { national } \\
\text { market } \\
\text { for } \\
\text { trading } \\
\text { GHG } \\
\text { emission } \\
\text { s } \\
\text { quotas. }\end{array}$ & $\begin{array}{l}\text { The role } \\
\text { of } \\
\text { technoanolo } \\
\text { gies in } \\
\text { NDC }\end{array}$ & $\begin{array}{l}\text { Carbon } \\
\text { Neutrali } \\
\text { ty Goal }\end{array}$ \\
\hline Russia & Yes & No & No & No & No \\
\hline $\begin{array}{l}\text { Kazakh } \\
\text { stan }\end{array}$ & Yes & Yes & Yes & Yes & $\begin{array}{l}\text { Yes } \\
(2060)\end{array}$ \\
\hline
\end{tabular}

Source: written by the authors.

Despite some common features, the domestic climate policy of the two countries has significant differences. Since 2010, Kazakhstan has been carrying out decisive institutional changes to strengthen the processes of environmental transformation of its economy. In 2013 the country adopted the concept of the transition to a green economy, formed a market for quotas for greenhouse gas emissions, announced the goal of achieving carbon neutrality by 2060 .

Russia lags behind the Republic of Kazakhstan in all the above-mentioned aspects of environmental modernization. The concept of "green economy" is practically absent in the official political discourse, the market for greenhouse gas emissions quotas is only in the initial stage. The introduction of new energy and resources like saving technologies, 
renewable energy sources, the development of alternative transport are all slowly taking place in Russia through ministerial resolutions and not within the framework of a national strategy. This slows down the processes of environmental modernization in the country. The lack of a clear vision of a country's development, based on a low-carbon economy, may leave it on the periphery of the world economy and cause destabilising processes in its social system.

\section{References}

1. Has the cold pole transformed into the hot pole? https://ria.ru/20200713/1574207225.ht $\mathrm{ml}$

2. Summer of 2020 in Kazakhstan, https://www.kp.kz/daily/217165/4265428/

3. B. Stahl, Internationale Politik verstehen (2020)

4. Share of renewable energy more than doubled between 2004 and 2019, https://ec.europa.eu

5. Y. A. Rusakova, Problems of international ecological safety and search for the diplomatic ways out (the xase of modern climate ntgotiations) (2016)

6. D. Otto, Global Climate Policy Handbook (2017)

7. C. Downie, M. Williams, Global Policy (2018)

8. J. Gupta, The History of Global Climate Governance (2014)

9. R. Leal-Arcas, Int. Affairs Forum, 4(1), 22 (2013)

10. G. Simonis, Global Climate Policy Handbook (2017)

11. M. Bemmann, B. Metzger, Ecological modernization (2014)

12. A.V. Sheludkov, The theoretical and practical issues, 2 (2015)

13. A. Stepanov, A. Burnasov, M. Ilyushkina, Y. Kovalev, G. Nyussupova, E3S Web of Conferences, 208, 03055 (2020)

14. A. Stepanov, A. Burnasov, M. Ilyushkina, Y. Kovalev, E3S Web of Conferences, 159, 02007 (2020)

15. A. Azyan, J. of Moscow State University, 1, (2015)

16. M. Olson, The Logics of collective actions. Social benefits and the theory of groups (1995)

17. A. Korppoo, A. Kokorin, Climate Policy, 17(2) (2017)

18. M. Jänike, Megatrend environmental innovations (2012)

19. W. Hein, J. Betz, D. Eucker, J. Hein, L. Holstenkamp, B. Neve, Global Climate Policy Handbook (2017)

20. M. Crippa, G. Oreggioni, Fossil CO2 and GHG emissions of all world countries 2020 (2020)

21. Frame convention of UNO on climate change, https://unfccc.int

22. Fossil CO2 and GHG emissions of all world countries (2019)

23. Climate protection index. The main results (2020), https://www.germanwatch.org/de/1 7281

24. N. Dronin, A. Bychkova, Development and Sustainability, 20(5) (2018)

25. D. Yagodin, Int. Political Science Review, 42(1) (2021)

26. L. Henry, L. McIntosh Sundstrom, Europe-Asia Studies, 64(7) (2012) 
27. Report from the Conference in Kyoto (1997)

28. Decision of the Marrakesh Ministry, 1/CP7, https://unfecc.int

29. Report on the results of the seventh session in Marrakesh 0n 29, https://unfccc.int

30. Doctrine of Climate in the Russian Federation, https://www.mnr.gov.ru/

31. The Decree of the Russian President on reducing the emissions, 752 (2013)

32. The transition of Kazakhstan towards the green economy, the Decree of the President (2013)

33. Intended Nationally Determined Contribution - Submission of the Republic of Kazakhstan, https://www4.unfccc.int 